\title{
Design optimization of Floor Cranes
}

\author{
A. Balaji \\ Department of Mechatronics \\ Engineering \\ Kongu Engineering College \\ Erode, India
}

\author{
H. Jahir Hussain \\ Department of Mechatronics \\ Engineering \\ Kongu Engineering College \\ Erode, India
}

\author{
M.R. Faheem Ashkar \\ Department of Mechatronics \\ Engineering \\ Kongu Engineering College \\ Erode, India
}

\begin{abstract}
This paper inculcates a way to make the floor crane as more efficient with less material requirement. This has been achieved by minimizing reach of the crane from the floor. The crane is assumed to be cantilever type. Also tension and acceleration in steel ropes are analysed to ensure the safety. The optimized crane successfully passed the various analysing tests which include deflection, bending moment, rope tension and acceleration of the loads in the rope. It also includes another method which provides the virtual user interface for the design engineer. By providing the crane dimensions in the virtual panel, the predefined program automatically creates the CAD modelling in the CAD software. The program is made with visual studio and Solid works macro. Finally, this work reduces the burden on the design engineer and increases the productivity.
\end{abstract}

Keywords: cranes; floor cranes; optimization; virtual CAD model; solid works

\section{INTRODUCTION}

A crane is a machine which is used in material handling processes. It is used to lift, lower and move any materials horizontally[1]. Cranes are used in construction, transportation, and manufacturing sections. It uses one or more simple machines to create mechanical advantage and thus move loads beyond the normal capability of a human[2]. Floor crane is taken into consideration in this work.

\section{PROBLEM STATEMENT}

Floor crane is shown in Figure 1 which has two columns for length $1 \mathrm{~m}$ and $1.2 \mathrm{~m}$. The design separates the two columns with the distance of $0.6 \mathrm{~m}$. The horizontal beam for about $1.5 \mathrm{~m}$ is defined as reach of the crane and it supports the rope. The whole crane is fixed at the base and the counter weight is loaded at the back. The problem is within the distance $0.6 \mathrm{~m}$, the design shoots up the length for about $0.2 \mathrm{~m}$. Hence the whole crane is modelled and analysed for deflection. The result shows that the deflection at the second column is very high.

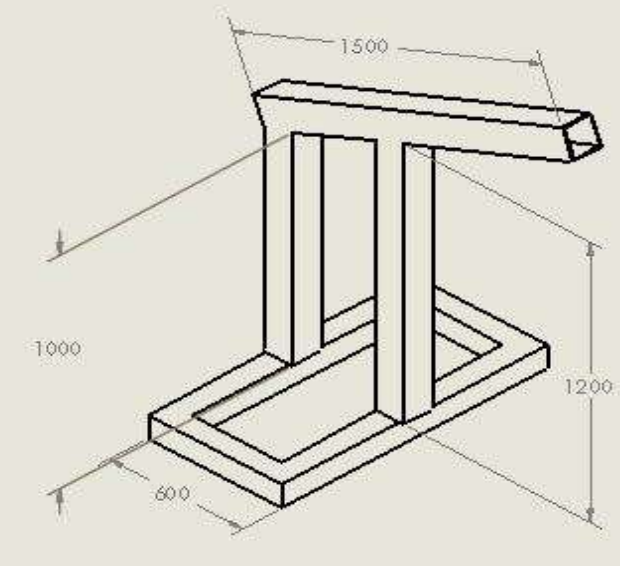

Figure 1 CAD model of floor crane

\section{VIRTUL CAD MODELING}

Floor crane design varies with capacity and reach of the crane. Depending on the reach, the length of the horizontal beam is varied. Hence, for every time the designer has to design the whole crane. In order to eliminate this problem, virtual CAD modeling[3] is proposed. Designer can modify the solid works macro in Microsoft visual basic, Microsoft visual studio for applications to fit the need.

\section{DESIGN OPTIMIZATION OF FLOOR CRANE}

In order to rectify the problem, the second column length is reduced from 1.2 meter to 1 meter. By doing so, the reach of the crane from the floor is reduced from $830 \mathrm{~mm}$ to $780 \mathrm{~mm}$ and angle of the rope beam is reduced from 22.2 degree to 10.8 degree. This final optimized design is analysed under various conditions to determine whether the design is safe and efficient in comparison with the previous design. Figure 2 shows the existing and optimized design of floor crane.

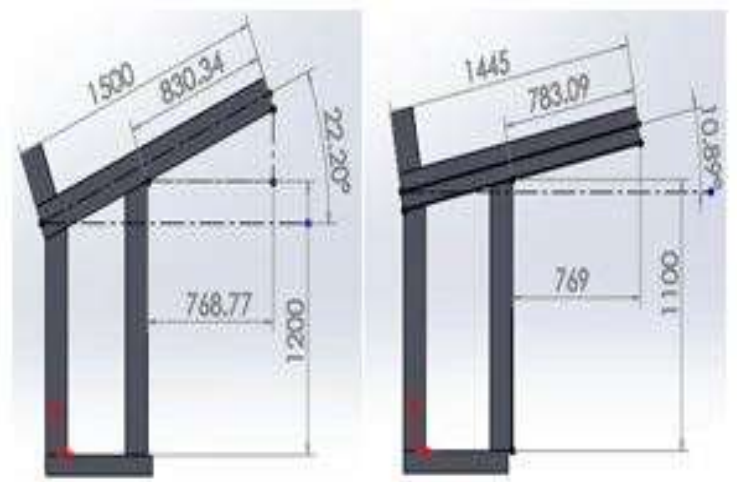

Figure 2 Existing and Optimized design of crane 


\section{DESIGN ANALYSIS}

\subsection{Bending Moment}

The column 1 and column 2 is rigidly fixed with the floor. Hence the beam in which the work outside the floor is considered as cantilever beam and analyzed for bending moment. The Figure 3 shows the calculation of bending moment. From the calculation, the bending moment in the optimized design is reduced about $23620 \mathrm{~N} \mathrm{~mm}$.
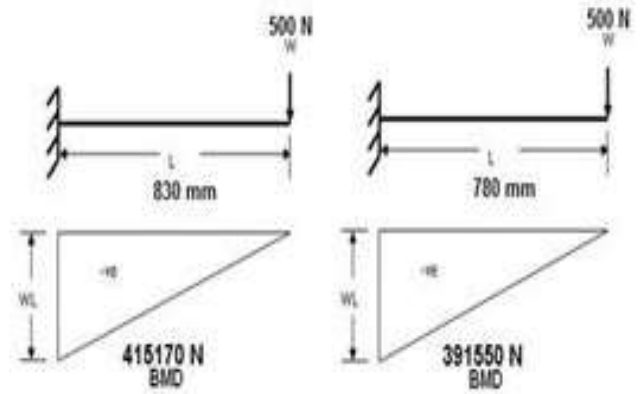

Figure 3 Bending moment calculation

\subsection{Deflection}

The deflection analysis of cantilever beam is analyzed which is shown in Figure 4. The material is Mild Steel and the details include young's modulus is $210 \mathrm{GPa}$; Poisson's Ratio is 0.3 and density about $7.85 \mathrm{~g} / \mathrm{cm}^{3}[4]$. From the result shown in figure 4 , the deflection of beam is reduced from $0.058 \mathrm{~mm}$ to $0.032 \mathrm{~mm}$.

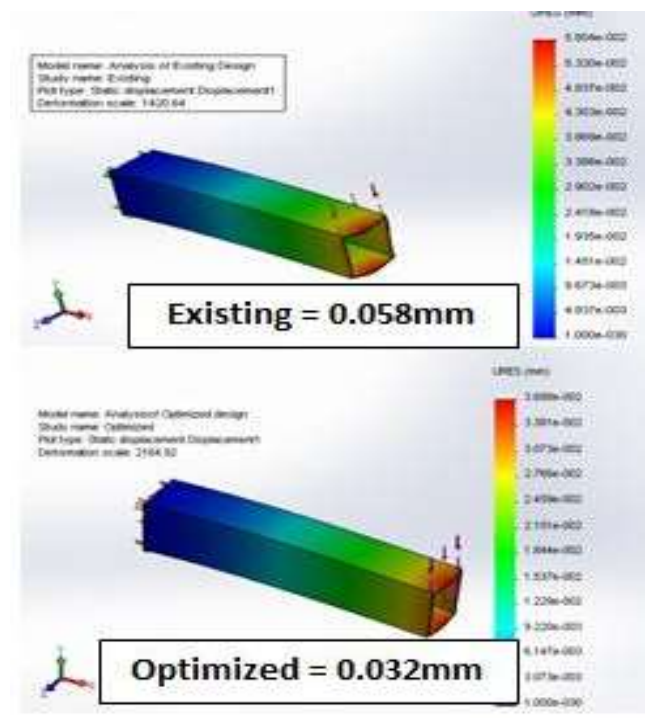

Figure 4 Deflection Analysis of Cantilever Beam

\section{SAFETY ANALYSIS}

\subsection{Rope Tension Analysis}

From the figure 2, the angle of the beam is changed from 22 degree to 10 degree. Based on the D' Alembert's principle, the tension and acceleration in the rope is calculated for sample loads. On resolving the forces in the figure 5, the tension and acceleration for the existing (angle $=22.2$ ) is about $12 \mathrm{~N}$ and $4.63 \mathrm{~m} / \mathrm{s}^{2}$ and for the optimized (angle = 10.89 ) is about $8.34 \mathrm{~N}$ and $5.26 \mathrm{~m} / \mathrm{s}^{2}$ respectively.

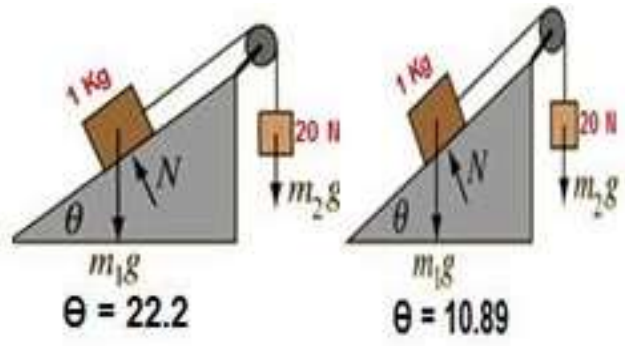

Figure 5 Force acting on different angles

Steel rope, used for lifting load, in the floor crane is modelled in Solid works and the sample tension is applied for the two different angles as shown in the figure 6 . The rope used is $6 * 7$ steel ropes with nominal diameter of $32 \mathrm{~mm}$. The result shows that deflection in the optimized angle is much lesser than the existing design.

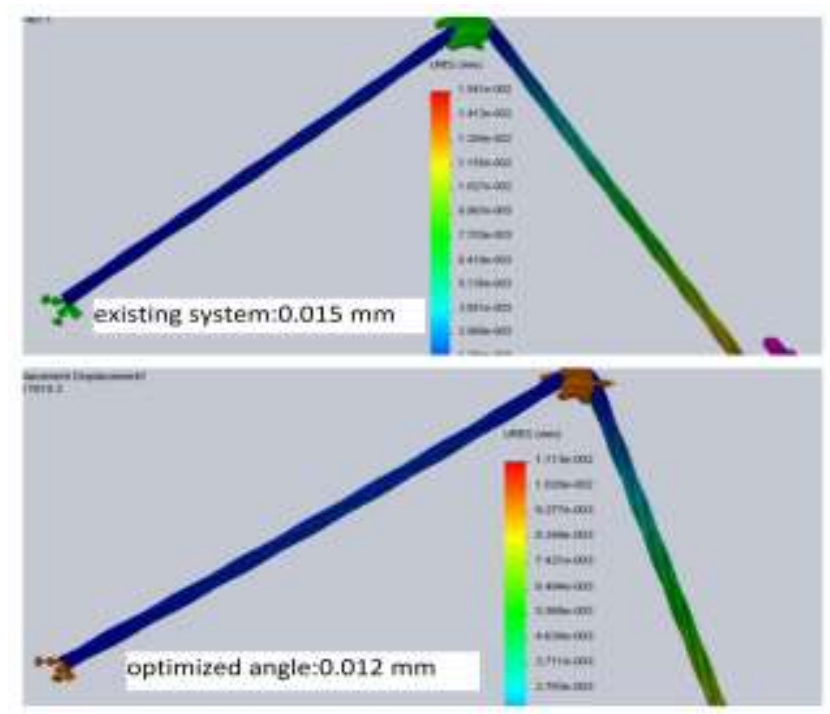

Figure 6 Rope Tension Analysis

\subsection{Load with acceleration}

From the rope tension analysis calculation, acceleration in the rope is also calculated. Hence, the load with acceleration is applied to both the existing and optimized design to check the deflection using Solid works simulation. The result as shown in figure 8 shows that the deflection in the optimized design is much lesser than the existing design. Figure 7 shows the applied initial acceleration in the rope.

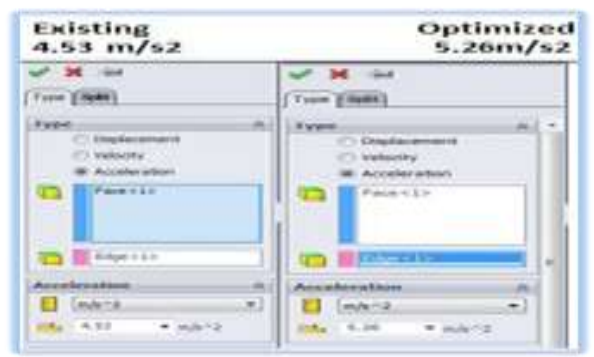

Figure 7 Initial conditions in solid works 


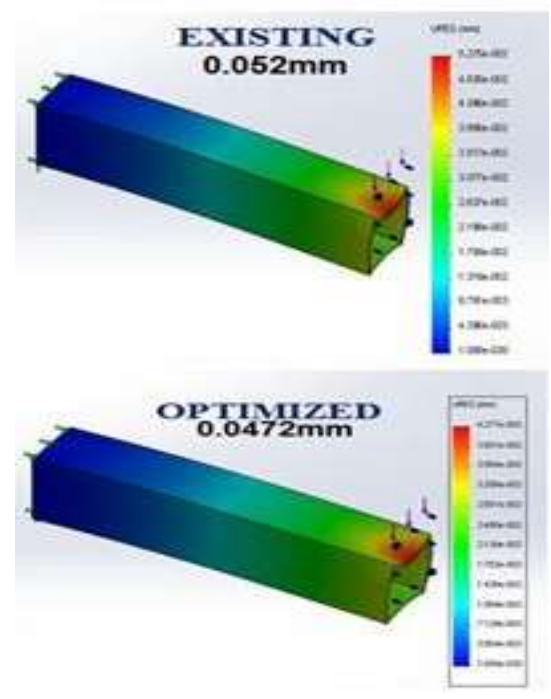

Figure 8 Deflection with acceleration analysis

\section{RESULTS}

The table 1 tabulates the advantage of optimized floor crane design over the existing one. Based on the analysis and results, the new optimized floor cane has been successfully fabricated which is shown in figure 9 .

Table 1 Comparative Study

\begin{tabular}{|c|c|c|}
\hline ANALYSIS & EXISTING & OPTIMIZED \\
\hline $\begin{array}{c}\text { Bending } \\
\text { Moment }\end{array}$ & $415170 \mathrm{Nmm}$ & $391550 \mathrm{Nmm}$ \\
\hline Deflection & $0.0587 \mathrm{~mm}$ & $0.0325 \mathrm{~mm}$ \\
\hline Rope Tension & High & Low \\
\hline $\begin{array}{c}\text { Deflection } \\
\text { with } \\
\text { Acceleration }\end{array}$ & $0.0527 \mathrm{~mm}$ & $0.0427 \mathrm{~mm}$ \\
\hline $\begin{array}{c}\text { Material } \\
\text { Requirement }\end{array}$ & More & Less \\
\hline \multicolumn{2}{|c}{} \\
\hline
\end{tabular}

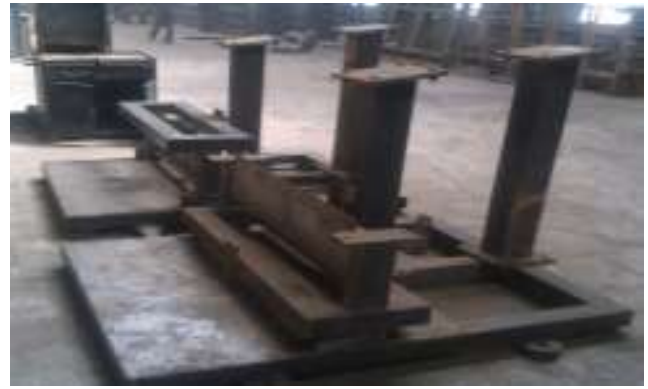

Figure 9 Optimized Floor Crane

\section{CONCLUSIONS}

[1] Crane would be safer (Rope tension is reduced)

[2] Crane would be stronger (Deflection and stress is reduced)

[3] Crane would be cheaper (Material requirement is reduced)

\section{REFERENCE}

[1] American Society of Mechanical Engineering (ASME), 'Electric Overhead Travelling CraneSpecifications and Details', Article 57, 2012

[2] American Society of Mechanical Engineering (ASME), 'Fixtures and loads for the Floor crane design', Article 72, 2010

[3] American Society of Mechanical Engineering (ASME), 'Steel Rope specifications and details', Article 57, 2012

[4] American Standard National Institute (ASNI), 'Types of Material Handling Cranes- overview', Article 63, 2008

[5] CAD sharp Journal, 'Solid works in Visual Studio', Article-13, 2011

[6] D. Saravanan, 'Solid works 2012 for Designers', $2^{\text {nd }}$ Edition, Wiley India Publications 